\title{
Willemsen Antropofágico: o criador da literatura brasileira na Holanda ${ }^{1}$
}

\section{Anthropophagical Willemsen: the creator of brazilian literature in the Netherlands}

Zelina Márcia Pereira Beato*

Universidade Estadual de Santa Cruz (UESC)

Ilhéus - Bahia / Brasil

RESUMO: Na leitura dos posfácios do tradutor August Willemsen presentes nas obras de alguns dos maiores escritores brasileiros publicados na Holanda, fica clara a noção de fidelidade que orienta seu trabalho de tradução. Willemsen reafirma sua promessa de fidelidade, seja quando justifica o que faz, seja quando confessa sua impotência em repetir o que julga ser o sentido do original. Neste texto, que faz parte de um projeto de pesquisa de pós-doutoramento, minha proposta é introduzir uma reflexão no campo da Linguística Aplicada Crítica em torno do tema da fidelidade, conceito tão caro aos Estudos da Tradução e que, invariavelmente, envolve as questôes da língua em seus vários funcionamentos: semântico, fonológico, sintático e cultural, ou seja, em todos os aspectos do uso da língua e de seus atributos linguísticos e culturais. No caso específico do trabalho de Willemsen, a reflexão aborda a promessa de fidelidade do tradutor, também declarada em entrevistas e ensaios, e as traduçôes criativas que, de fato, produz. A tese que anima essa abordagem é de que, mesmo declarando sua fidelidade aos autores que ama e traduz, considerando-se a visão tradicional de fidelidade como repetição da totalidade do sentido, Willemsen e seus protocolos tradutórios estabelecem com a língua da tradução os mesmos mecanismos criativos que o autor estabeleceu com a língua do original. Nesse sentido, as traduçōes criativas de Willemsen sinalizam para uma noção de fidelidade que foge à expectativa de apagamento autoral do tradutor. Avançando na ousadia da análise, não é difícil articular a proposta tradutória de Willemsen com o conceito de transcriação concepção de tradução criativa antropofágica elaborada por Haroldo de Campos. PALAVRAS-CHAVE: August Willemsen, tradução criativa, transcriação, literatura brasileira.

*zmpbeato@uesc.br

${ }^{1}$ Primeiros estudos de um projeto de pesquisa de pós-doutoramento junto ao Centre for Translation Studies CETRA, da Katholiek Universiteit Leuven, Bélgica, e ao Opleiding Portugese Taal en Cultuur, da Universiteit Utrecht, Holanda. 
ABSTRACT: August Willemsen's afterwords in the translated works of the most well known Brazilian authors published in the Netherlands, most generally, present his promises of fidelity as he accounts for his work of reading and translating. With the same assurance, he confesses his inability to repeat the significations he ascertains in the original texts. In this paper, which is part of a pos-doctoral project, my proposal is to introduce a discussion from the perspective of Critical Applied Linguistic of the old age concept of fidelity which involves aspects of language in its several linguistic operations: semantic, phonological, syntactic and cultural, that is, all the aspects of language use and and its cultural and grammatical attributes. My primary intention is to confront the translator's promises, stated in interviews, essays and papers, and the creative translations he, in fact, produces. The thesis that orientates this critical reading is that, considering the traditional notion of fidelity as repetition of the totality of signification and despite his genuine intention to be faithful to the authors he loves and translates, Willemsen and his translation protocols battle to reproduce, in the target language, similar creative mechanisms at work in the source language. The creative translations proposed by August Willemsen anticipate a revolutionary sense of fidelity which eludes the expectation of authorial transparency nurtured by tradition. Willemsen's translation project is not unfamiliar with the concept of transcriation - the creative translation concept fostered by Haroldo de Campos's "anthropophagic theory".

KEYWORDS: August Willemsen, creative translation, transcriation, Brazilian literature.

Maar meneer Willemsen, die Portugezen van $u$, die spreken Nederlands...2

Theo Sontrop

\section{Introdução}

Quando perguntado sobre o motivo de ter escolhido justamente o português como foco principal de seus estudos, August Willemsen, o maior tradutor da literatura lusófona para o neerlandês, se espanta e retruca:

Sempre achei esquisita essa pergunta. Por que é que não me interessaria por uma língua falada por umas 160 milhóes de pessoas no mundo, e que é, numericamente falando, a terceira língua do mundo ocidental, depois do inglês e do espanhol? Por que é que não me interessaria por uma literatura como a portuguesa, com capítulos como a lírica medieval, Fernão Lopes, Gil Vicente, Camões, Antônio Vieira, Eça de Queiróz, Fernando Pessoa - tudo grande literatura? Por

${ }^{2}$ Mas Senhor Willemsen, os seus portugueses, eles falam holandês....”. 
que é que não me interessaria por uma literatura como a brasileira, com autores como Machado de Assis, Graciliano Ramos, Guimarães Rosa, Dalton Trevisan, poetas como Manuel Bandeira, Carlos Drummond de Andrade, João Cabral de Melo Neto - tudo grande literatura? O que surpreende aqui não é, ou não deveria ser, o meu interesse por essa língua, mas o fato de alguém perguntar pelos motivos desse interesse (WILLEMSEN, 1986, p. 35).

Interesse é o gesto visível de uma força que não se explica. Willemsen relata nesse mesmo texto seu primeiro contato com a literatura brasileira, ainda nos anos 1950: "li a tradução holandesa de um livro brasileiro - Os Sertôes, de Euclides da Cunha. O efeito do livro foi fulminante: meses seguidos chateei meus amigos com a história de Canudos" (WILLEMSEN, 1986, p. 56). Foi esse primeiro encontro e a vontade confessa de seguir os desejos por ele despertados, aprender a língua para ler o livro no original e, eventualmente, visitar os lugares na história retratados que transformaram Willemsen no maior tradutor do português nos Países Baixos.

Da mesma forma, Willemsen não precisa explicar os motivos de ter dedicado 31 anos de sua vida à tradução de autores portugueses e brasileiros, já sabendo que só traduzimos os autores, as literaturas e as línguas que amamos. Ao longo de 37 anos, com uma longa interrupção de seis, Willemsen produziu traduções que se transformaram em 52 volumes, entre romances, coletâneas de poesia e contos. Segundo Taco Schreij (2009), de 1970 a 1986, Willemsen publicou dezenove volumes de traduções, seguindo-se uma breve interrupção de seis anos, e de 1992 a 2007, foram publicados mais 33 títulos.

Ao traduzir apenas seus autores preferidos, Willemsen estabeleceu uma relação especial com seus editores, convencendo-os de que esses autores eram vendáveis. Como registra Walter Carlos Costa, "a partir de certa altura, o fato de ele ser o tradutor de uma obra já garantia, de fato, certo sucesso comercial prévio à tradução" (COSTA, 2007, p. 181). É unânime a percepção de que o prestígio de que desfruta a literatura brasileira na Holanda deve muito ao trabalho de Willemsen: primeiro, por ter escolhido autores de grande representatividade, e segundo, pelas traduções feitas "com maestria" (COSTA, 2007, p. 187). Seu apuro estilístico lhe valeu, em 1983, o prêmio Martinus Nijhoff Prize.

Willemsen também publicou seus próprios livros, ensaios e textos memorialísticos, repetindo o sucesso com a crítica e o público. Em 1986, obteve o prêmio Lucy B. \& C.W. van der Hoogt por seu Braziliaanse brieven 
(Cartas Brasileiras), uma compilação de cartas em que relata as quatro viagens que fez ao Brasil, cheias de anedotas e de suas experiências com a terra, o povo, a cultura e os conservadores compatriotas que encontrou no Brasil. Em 1994, escreveu De goddelijke kanarie (O canário divino), sua experiência pessoal com o futebol brasileiro, de que era grande conhecedor.

Willemsen nasceu em Amsterdã, em junho de 1936, e, depois de estudar piano por alguns anos, resolveu dedicar-se ao estudo da língua e da literatura portuguesas, tornando-se professor da Universidade de Amsterdã. Apesar do sucesso também como escritor, Willemsen é mais conhecido por seus trabalhos como tradutor. Em um número considerável das traduçôes que publicou, Willemsen acrescentou posfácios, ${ }^{3}$ ou seja, uma longa nota do tradutor, na qual busca lidar com todas essas questões: $\mathrm{o}$ amor que não se explica, a língua portuguesa, o idioma autoral e a singularidade da assinatura de cada um de seus autores. Testemunha da visão que Willemsen tem da obra de Guimarães Rosa, por exemplo, é o título do posfácio que acompanha a tradução de Grande sertão: veredas: "Het woord als gedicht - het book als de wereld" (A palavra como poema - o livro como o mundo). Esse título é revelador da dimensão que a língua de Guimarães Rosa representa para Willemsen. Sem mencionar a inquietação com os neologismos de Rosa, o tradutor ainda deve lidar com o sentido fortemente marcado pelo regionalismo da narrativa. No primeiro parágrafo, Willemsen pergunta: "O que significa Sertão?", e acrescenta: "Não pense que o sertão seja menos estranho ou desconhecido para um morador do Rio de Janeiro do que é para um leitor holandês" (WILLEMSEN, 2000, p. 529).

Essas reflexōes são apenas uma pista das inquietações com que teve que se haver Willemsen ao traduzir a língua roseana. Esses posfácios são, em suma, o registro que o tradutor faz dos momentos em que a tradução estancou. Algo barrou a possibilidade pretendida de fidelidade, entendida como "repetição do mesmo sentido do original". Nesses momentos, Willemsen teve de elaborar uma solução que é própria, certamente obedecendo a escolhas e soluçōes que só ele poderia produzir. Essas soluçóes são, na verdade, uma forma de contra-assinatura nos arquivos que escolheu herdar, impondo-lhe uma tarefa específica - a tarefa de traduzir.

\footnotetext{
${ }^{3}$ Não há um levantamento de referência seguro e abrangente sobre o número desses posfácios. Considerando, entretanto, a regularidade com que é mencionada sua existência nas obras traduzidas citadas em bibliografias, a expectativa é de que haja posfácios na maioria dos livros traduzidos por Willemsen.
} 
Apesar do sucesso da literatura brasileira na Holanda e desse tradutor apaixonado por Guimarães Rosa, pela literatura brasileira e o Brasil, seu trabalho é praticamente desconhecido para o meio acadêmico e literário brasileiros. As informações até aqui reunidas foram, com exceção de alguns textos de estudiosos da Universidade Federal de Santa Catarina, em sua maior parte, recolhidas de fontes estrangeiras. $\mathrm{O}$ trabalho tradutório criativo de August Willemsen é responsável pelo sucesso que a literatura brasileira atingiu na Holanda, diferente do destino mais discreto que teve em outros países da Europa. Apesar disso, seu trabalho é desconhecido no Brasil, ao contrário do trabalho de outros tradutores de Guimarães Rosa, como Edoardo Bizzarri, Curt Meyer-Clason ou Harriet de Onís, cujas cartas trocadas com o autor de Grande sertão: veredas são fontes inesgotáveis de consulta de muitos acadêmicos de diversas áreas de estudo.

Nesse contexto, a pesquisa de que esse texto é apenas um relato introdutório pretende contribuir para tornar esse valioso trabalho conhecido da comunidade acadêmica brasileira e, ao mesmo tempo, produzir uma reflexão sobre o conceito de fidelidade que marca o trabalho desse tradutor holandês. O conceito de fidelidade como repetição fiel e literal do original é um eterno fantasma que acompanha os Estudos da Tradução desde as primeiras reflexōes produzidas por São Jerônimo a propósito da tradução da Bíblia. Não por acaso, a noção de fidelidade permanece profundamente marcada pela tradição judaico-cristã. A tarefa de traduzir o texto sagrado está orientada pela exigência do literalismo, já que as palavras e seu arranjo nas frases são o próprio mistério divino. $\mathrm{O}$ tradutor tem, pois, como exigência, nada mais, nada menos que repetir a palavra de Deus. O tradutor Willemsen, mesmo que sua prática desafiasse suas intenções, não colocou sua expectativa de fidelidade confessa sob uma perspectiva diferente daquela de fidelidade como repetição dos sentidos do original em face do apagamento da figura do tradutor.

\section{Herda}

Num diálogo entre Elisabeth Roudinesco e Jacques Derrida (2001), provocado por ela, Derrida reflete longamente sobre o tema da herança. Naquele momento, falavam de herança teórica, obviamente pensando no trabalho de Derrida como leitor e herdeiro da reflexão teórica monumental que se produziu na segunda metade do século XX. Derrida dedicou-se a reler esses 
marcos do pensamento ocidental e a desconstruí-los. ${ }^{4}$ Para Derrida, ler e descontruir são uma forma de traduzir. Os textos que apresentam a leitura derridiana de obras canônicas - Claude Lévi-Strauss, Michel Foucault, Louis Althusser, Jacques Lacan, Freud, Saussure, só para citar alguns - são uma forma de se explicar com essa tradição herdada, sem jamais deixar de reivindicar a importância que tiveram em seu próprio percurso. Derrida reafirma-se como herdeiro, mas de um ponto de vista daquele que escolhe o legado: "daquilo que não admiro, eu não falo jamais” (DERRIDA; ROUDINESCO, 2001, p. 18). Mas, se a herança é uma escolha orientada pela admiração e pelo reconhecimento, não há escolha diante da tarefa que nos é imposta - ser fiel à herança a fim de reinterpretá-la e reafirmá-la, relançando-a ao futuro. Como afirma, então, Derrida,

só um ser finito herda e sua finitude lhe impõe uma dupla injunção. Ela o obriga a receber aquilo que é maior, mais velho, mais poderoso e durável que ele próprio, ao mesmo tempo em que lhe impóe escolhas, preferências, sacrifícios, exclusões, abandono. Justamente para responder ao apelo que lhe precede, para responder a ele e responder por ele, em seu nome como no nome do outro (DERRIDA; ROUDINESCO, 2001, p. 18).

O herdeiro torna-se responsável e duplamente endividado com aquilo que recebe: o passado e igualmente o futuro, o que também vai deixar como herança. Aceitar uma herança é reconhecer o nome próprio que assina o arquivo herdado, sabendo que a demanda que acompanha a herança é de contraassinatura sobre aquele arquivo. Na visão de Derrida, portanto, herdar um arquivo significa aceitar a herança, honrando-a de duas maneiras: repeti-la, reafirmando-a, e relançá-la, contra-assinando, isto é, sendo fiel ao arquivo herdado e, ao mesmo tempo, colocando uma marca própria no momento de oferecê-la a outro, o que não pode acontecer sem um gesto criativo. Como afirma: "anteceder o nome daquele que nos antecede, e anteceder o próprio nome! Inventar seu nome próprio, assinar de outro jeito, cada vez de uma forma única, mas em nome do nome herdado, se é que isso é possível!" (DERRIDA; ROUDINESCO, 2001, p. 18).

\footnotetext{
${ }^{4}$ Esse termo forjado por Derrida vem emprestado da arquitetura, indicando a decomposição de uma estrutura. Derrida, elaborando o texto em torno de seus momentos cegos, trabalha para desfazer e denunciar, sem jamais destruir, um sistema falo-fonocêntrico de pensamento hegemônico e dominante.
} 
Se Derrida falava, então, sobre herdar um arquivo teórico, nada difere se mudarmos a perspectiva para falar de arquivo literário - considerando que Derrida diria mesmo que arquivo teórico ou literário é, de fato, uma mudança de perspectiva ou de abordagem, visto que qualquer um pode, em alguns contextos, ser tomado como o outro. O risco que sofre a herança não é unicamente de traição. Sem o herdeiro que venha contra-assinar a herança recebida, seu destino seria permanecer em silêncio, esquecida e absolutamente intraduzível. Sem a tradução, o arquivo não existe como possibilidade de acesso em outro lugar. Nas palavras de Grégoire Biyogo,

a questão da herança coloca em evidência dois movimentos simultâneos e inversos: por um lado trata-se de preservar e apresentar o espírito e a letra de uma tradição. Por outro, trata-se de uma certa maneira de trair a aquisição que correria o risco de ficar congelada (BIYOGO, 2005, p. 47).

Essa lógica da herança, do arquivo que recebemos assinado, da dupla demanda de fidelidade e da situação de dívida impagável descreve de maneira exemplar a tarefa do tradutor - outro nome para o impossível. O tradutor está irremediavelmente enredado pelo que Derrida chama de double bind: a tarefa necessária e impossível de traduzir. Diante do autor e do texto original, o tradutor que se entrega à tarefa de tradução assume um compromisso de fidelidade. $\mathrm{Na}$ tradição teórica tradicional, essa fidelidade está associada à repetição fiel dos sentidos do original, de respeito e reprodução das intençôes do autor. Ao mesmo tempo, o tradutor também assume um compromisso com a comunidade de destino da tradução, que é o de oferecer aquilo que supostamente foi dado pelo original. Há uma dupla dívida assumida, dupla demanda de fidelidade e de garantia de verdade: para com o autor do original e para com o leitor da tradução. Todavia, o tradutor, mesmo que honesta e duplamente comprometido, dá-se conta de que não pode cumprir a tarefa na dimensão que dele espera a visão tradicional da tradutologia. $\mathrm{O}$ tradutor sabe os limites da língua, e sofre.

\section{A melancolia por não ser fiel}

A sujeição ao double bind ajuda a entender a melancolia que se atribui ao tradutor que trava uma batalha inglória com as línguas envolvidas na tradução. Suzana Kampff Lages (2002) expõe, em Walter Benjamin: tradução e melancolia, esse drama do tradutor e o vínculo estreito entre tradução e a disposição melancólica. 
Dividido entre o desejo de dar vez e voz ao outro, ao autor do original, e o esforço necessário à acumulação de múltiplos saberes (lingüísticos, históricos, culturais, psicológicos) para cumprir sua tarefa, o tradutor oscila, todo o tempo, entre duas atitudes opostas e complementares: ele é ou um "coitado" ou um "herói" (Paulo Rónai), ele passa da humildade à soberba (José Paulo Paes) e da depressão à mania como, justamente, um exímio melancólico. Na medida em que ele admira o outro, o original, a autoridade do autor, ele se apaga a si mesmo para melhor deixar brilhálo; ele insiste em dizer que não consegue, por princípio e malgrado seus hercúleos esforços, devolver na sua língua a riqueza do texto original; sem empreendimento é, desde sempre, fadado ao fracasso, já que não pode tornar-se transparente (Meschonnic) ou invisível (Venuti) e que, mais fundamentalmente, as línguas são sistemas autônomos fechados, portanto intransponíveis (Mounin). Simultaneamente o tradutor sofre essa autodesvalorização e se sente como que "engolido", devorado pelo texto alheio, podendo até se rebelar contra esse monstro por ele construído [...] Mas as ligações entre tradução, melancolia e narcisismo não se deixam resumir entre uma auto-afirmação ruidosa de si mesmo e uma silenciosa submissão à voz do outro (LAGES, 2002, p. 12).

Walter Benjamin, no seu texto monumental sobre a tarefa do tradutor, sinaliza para a melancolia usando várias metáforas para falar de língua, de tradução, da impossibilidade dessa tarefa, do sagrado no original que a tradução inescapavelmente só vai tangenciar, da perda constitutiva e originária. Segundo Benjamin, é unicamente no momento fugaz da relação entre a tradução e o original que a tradução pode libertar a língua cativa no original, reconciliandoas na tradução. Para esse teórico, a tarefa do tradutor é, em última instância, "redimir na própria, a pura língua, exilada na estrangeira, liberar a língua do cativeiro da obra por meio da recriação - essa é a tarefa do tradutor" (BENJAMIN, 2008, p. 303).

Nessa relação entre tradução e melancolia, tratada com maestria por Suzana Kampff Lages, como ela mesma resume, ${ }^{5}$ se, por um lado, há um modelo tradicional de tradutor altamente idealizado que estoicamente resiste a toda tentativa de desmontagem e de quem se exige transparência e humildade diante do objeto sacralizado que se sabe, desde são Jerônimo, inapreensível em sua totalidade; por outro, desse mesmo tradutor, tem-se a expectativa de "herói da hermenêutica textual”, que deverá se incumbir da compreensão total dos sentidos do texto e das intençôes do autor, mesmo que estejam encalacrados

${ }^{5}$ Ver Lages (2002, p. 65-72). 
com razões inconscientes. Se tem como tarefa uma empreitada hercúlea de antemão impossível, a descrição desse tradutor ideal não podia deixar de associar ao complexo de inferioridade o seu equivalente contrário, o ideal de onipotência detentora de "conhecimentos enciclopédicos, quase universais" (LAGES, 2002, p. 68).

Lamentar a perda da língua original e constatar os próprios limites nessa tarefa metafísica de repetição do mesmo relaciona a melancolia e a única escolha que resta: transformar, criar e recriar o original como opção de sobrevida. Convocando o tradutor a um papel de protagonista, responsável pelo original que escolheu herdar e relançar adiante, consciente

dessa violência inevitável, necessária, enfim, simultaneamente vital e mortal, que é o móvel de todo trabalho de tradução preocupado com seu próprio fundamento histórico e ontológico, como manifestação de uma escrita que não esconde a duplicidade de sua autoria (LAGES, 2002, p. 82, grifos da autora).

\section{A criação para ser fiel}

Ao texto literário, tradicionalmente, atribui-se uma carga de sentidos maior que aos textos não literários, e o tradutor que se aproxima de uma obra literária, mais que qualquer outro agente tradutor, sente-se endividado com o autor e seus sentidos. $\mathrm{O}$ irônico é que, da obra literária original, o que se perde no processo de tradução é exatamente o significante - a própria materialidade da letra. A língua é, literalmente falando, a primeira vítima da tradução, que, ao ser abandonada, necessariamente convoca o gesto interpretativo que vai privilegiar determinados sentidos apartados da cadeia semântica a que pertence o original. Distante da abordagem melancólica que quantifica perdas e ganhos linguísticos do processo de tradução, os estudos da tradução que incorporam os aspectos históricos, culturais e políticos reconhecem "a importância fundamental da perda, do distanciamento, da separação, para a constituição de uma identidade" (LAGES, 2002, p. 83). No Brasil, os estudos sobre tradução que reivindicam a autonomia cultural do texto traduzido teve nos irmãos Campos uma referência exemplar das estratégias de tradução de caráter heterogêneo - "a tradução do 'outro tipo', a que os poetas concretistas brasileiros denominaram, na esteira da classificação de Jakobson, transposição criativa ou 'transcriação"” (LAGES, 2002, p. 78). A tradução torna-se “outra”, diferente da pretendida cópia que mal representa o texto original. 
A tradução ocupa um lugar estratégico no projeto concretista dos irmãos Haroldo e Augusto de Campos e de Décio Pignatari, ao incorporar o conceito de "antropofagia" de Oswald de Andrade. O movimento literário antropofágico da Semana de 1922 preconizava a "deglutição" da cultura do outro, sem negarlhe o valor, mas também sem imitá-la acriticamente. No "Manifesto Antropófago", em que critica as elites brasileiras que se submetiam à cultura dos países desenvolvidos, Oswald de Andrade propunha a deglutir a produção cultural importada para reelaborá-la e, então, torná-la produto de exportação. ${ }^{6}$ $\mathrm{Na}$ perspectiva da tradução, a antropofagia como estratégia de leitura vai significar uma forma de apropriação violenta, com base na seleção e releitura do estrato poético, acionando uma estratégia tradutória que reproduz na outra língua "elementos da estrutura, da articulação entre significantes e os recursos poéticos da paranomásia” (JAKOBSON, 1971, p. 66).

No processo tradutório, a ousadia da tradução criativa pode pôr em marcha mecanismos de significação que, na língua da tradução, acionam um funcionamento similar ao que o tradutor percebe em operação na língua do original. No caso do trabalho tradutório de Willemsen, as soluçôes mais radicais de inventividade parecem responder melhor à sua expectativa de fidelidade, reeditando certo funcionamento da língua que ele identifica presente na relação do autor com o original.

Willemsen teve a bravura de traduzir Grande sertão: veredas, uma obra considerada intraduzível, idiomática, profundamente marcada por uma sofisticada elaboração linguística, tanto quanto pela singularidade do universo sertanejo do interior de Minas Gerais. Guimarães Rosa tem o perfil dos escritores que operam "de maneira consciente e, mesmo, programática com a pós-babélica confusão linguística e a culpa dela derivada" (LAGES, 2007, p. 158), a exemplo de James Joyce, Beckett, Nabokov ou Franz Kafka, ou seja, todos aqueles escritores para os quais "a questão da língua ultrapassa as fronteiras nacionais e avança para se instalar em territórios fronteiriços, limiares, umbrais, entre-lugares" (LAGES, 2007, p. 158).

Ao traduzir um conto do livro Primeiras estórias, de Rosa, Willemsen deparou-se com uma passagem de "Partida do audaz navegante" (traduzido como "Vertrek van de kloeke zeevaarder"):

${ }^{6}$ Ver Andrade (1928, p. 3, 7). 
Vão com Deus! mamãe disse, profetisa, com aquela voz voável. Ela falava, e choviam era bátegas de bênçãos.

Em neerlandês, o trecho se transformou em: ${ }^{7}$

Ga met God! riep moeder, voorzeggend, met die ontstijgende stem. Haar spreken was als regen: een zeiken van zegeningen.

Em uma palestra no Latijns Amerika Centrum (LAC) de Amsterdã, em 2006, Willemsen justifica a sua solução:

Mas no fim havia "bátegas de bênçãos". A tradução literal, "slagregens van zegeningen", não me parecia bonita e não tinha a aliteração do original. Aí pensei que quando chove muito, dizemos "Het regent dat het zeikt" [chove de entornar]: daí me veio "een zeiken van zegeningen" [forte chover de bênçãos]. Mas, então, pensei: "Isso é impossível", mas acabei deixando e depois pensei: "E por que não? se soa tão bem?" Para aplacar minha consciência, fui ao dicionário e, dos quatro significados encontrados havia dois regionais equivalentes a "cair água" e "chover forte". Ou seja, independentemente de meu gosto pessoal, eu estava autorizado a usar a palavra (WILLEMSEN apud COSTA, 2007, p. 37).

Essa explicação que Willemsen antecipa para suas escolhas tradutórias nitidamente busca aliviar a consciência que lhe cobra fidelidade, concebida como repetição de signos. Como ele próprio afirma, buscaria aplacar a culpa melancólica ao perceber que diz outra coisa, que não faz uma tradução literal e que, afinal, indevidamente, pode não estar sendo fiel ao original de Rosa. Para sustentar que "een zeiken van zegeningen" é uma boa tradução para "bátegas de bênçãos", Willemsen justifica que "a tradução literal não parece bonita e não conserva a aliteração do original"; do mesmo modo, defende sua solução, "soa tão bem". Finalmente, Willemsen se protege ao usar como escudo a autoridade do dicionário, "havia dois regionais equivalentes".

Seus argumentos, a despeito de enriquecerem nossas reflexões sobre o processo de tradução, em nenhum momento sustentam as escolhas feitas e a tradução produzida. Senão, como justificar o preciosismo do tradutor na proteção do título do poema "Profundamente", de Manuel Bandeira? Esse

\footnotetext{
${ }^{7}$ Vá com Deus, disse a mãe, predizendo, com voz transcendental. Seu falar era como a chuva: um gemido de bênçãos. (minha tradução livre da tradução de Willemsen).
} 
texto foi traduzido por Willemsen e recebeu em holandês o título "In diepe slaap". Em entrevista a Sander de Vaan, em abril de 2007, Willemsen afirma sobre a palavra que dá título ao poema de Bandeira:

Você sabe, é claro, que ela é apenas o advérbio de "profundo". Não temos [em neerlandês] uma forma separada para o advérbio, e na tradução alemã - acredito que seja de Curt Meyer-Clason - é simplesmente Profundo. Não me agrada. O comprimento da palavra, com as quatro sílabas, para mim, é um correlato da profundidade do sono, do primeiro sono e eventualmente da morte. Talvez isso seja bobagem, mas eu não acho que você possa descartar uma sílaba. Por isso, Em sono profundo - quatro sílabas também. Eu pensei que era preciso que assim fosse (Willemsen, 2007, [n.p.]). ${ }^{8}$

Não há, portanto, qualquer argumento do ponto de vista da língua em seus estratos semânticos que, de fato, possa sustentar as duas abordagens diferentes com que Willemsen se aproxima dos problemas tradutórios com os quais se depara. Na tradução do trecho do livro de Guimarães Rosa, o tradutor se permite abandonar a estratégia da literalidade em nome de uma solução que "soa tão bem", mas que, estritamente considerada, diz outra coisa. No título do poema de Manuela Bandeira, entretanto, Willemsen considera inadequado "descartar uma sílaba".

Willemsen coloca-se como herdeiro de textos e de palavras da língua portuguesa ao se oferecer como tradutor de obras da literatura lusófona. Nessa posição, assume a condição de devedor de uma dívida impagável, tanto com relação ao original quanto com relação à tradução, na promessa àquele de quem herda e na promessa àquele a quem entrega o objeto herdado. Ciente da impossibilidade de atender à dupla injunção de fidelidade, Willemsen apresenta justificativas fiadas no campo semântico, fonético e gramatical, fazendo supor a possibilidade de fidelidade nesse estrato de funcionamento da língua. Entretanto, suas justificativas não podem ser consideradas a salvo das incoerências, visto que, do ponto de vista da língua, a aderência entre o problema imposto pelo original e a solução oferecida na tradução não se dá, de fato, por correspondência clara e inequívoca. Como fundamentar, do ponto de vista do uso da língua, a solução que se justifica pelo mesmo número de sílabas do título do original? Ou, ainda, como aceitar que a tradução literal seja descartada porque essa "não me parecia bonita e não tinha a aliteração do original"?

${ }^{8}<$ http://meandermagazine.net/magazines/mea316.html>. 
Não gostaria de adiantar aqui a expectativa de que qualquer outra solução ou justificativa linguística oferecida por Willemsen bastaria ou seria boa o bastante a ponto de sustentar ter ele sido mais ou menos fiel ao texto de Guimarães Rosa ou ao poema de Bandeira. Se formos absolutamente radicais no atendimento ao conceito de fidelidade como repetição do mesmo, teremos que considerar que de forma alguma a tradução da palavra table do inglês para mesa no português se processa no campo da repetição do mesmo, visto que, no inglês, a palavra table se distingue de desk para nomear peças da mobília que no Brasil se confundem. Isto é, na língua inglesa, as palavras table e desk nomeiam móveis que se distinguem segundo o uso que dessas peças se faz. No Brasil, distintamente, a palavra mesa nomeia uma peça da mobília que se constitui segundo um formato específico, indiferente aos usos que desse móvel são feitos. A conclusão a que chegamos é de que a tradução de uma palavra pela outra se faz indiferente ao funcionamento distinto que cada uma tem nos sistemas linguísticos a que pertencem. Dessa forma, vemos que as palavras mesa e table, rigorosamente falando, não se sobrepõem como "mesmas".

Definitivamente, nos momentos em que justifica seu trabalho como tradutor, August Willemsen não sustenta de maneira inequívoca e do ponto de vista do uso da língua as soluçóes que engendra. Ao contrário, seus argumentos testemunham, de um lado, seus amores pela literatura de língua portuguesa, pelos autores, pelas obras, pelo jogo da linguagem poética, e, de outro, seu poder autoral impulsionado por sua pulsão criativa e grande habilidade na lida com as línguas com as quais trabalha.

\section{Considerações finais}

O grande fantasma que ameaça os tradutores é a infidelidade, por, supostamente, alterar o sentido do texto original. Mesmo sendo generoso com Willemsen, aceitando seus argumentos e aliviando sua consciência, o certo é que "een zeiken van zegeningen" diz outra coisa que "bátegas de bênçãos". Willemsen não discordaria disso, a tomar por base a mesma entrevista com Sander de Vaan, que recupera um dos ensaios de Willemsen publicado em 1979, no qual o tradutor afirma: "(a boa) [...] poesia é aquela que não poderia ser dita com outras palavras". ' Willemsen surpreende-se de ter afirmado aquilo

${ }_{9}^{9}$ No original: "(goede) [...] poëzie is dat wat niet ook met andere woorden gezegd had kunnen worden". 
tantos anos antes, mas emenda: "naquele nível [da linguagem] a poesia funciona como a piada, se você explica - conta com outras palavras - perde toda a graça” ${ }^{10}$ Essa afirmativa, tomada rigorosamente ao pé da letra, não se reconcilia com a tradução, que não faz outra coisa senão usar "outras palavras". O corpo da palavra é, por excelência, aquilo mesmo que se perde na tradução. Apesar de desejar o contrário, mesmo desejando ser fiel ao autor e ao texto original, é inegável que o sucesso das traduções de Willemsen deve muito ao seu talento criativo, ao seu talento como artífice das "outras palavras". Como o herdeiro que escolhe a herança linguística e literária a ser herdada, Willemsen elegeu autores de língua portuguesa para traduzir e fazer chegar a seus compatriotas os textos que amava. Como todo herdeiro, ele prometeu honrar a herança recebida no texto e na língua. São sempre promessas de fidelidade, uma vez que também o texto e a língua se instauram na promessa: a promessa de doação do sentido. Todo texto, ou toda palavra, no fundo são uma promessa de sentido. A despeito de sua dupla promessa de fidelidade, Willemsen não pôde, nem jamais poderia honrar sua dívida no sentido mais tradicional de fidelidade como repetição do mesmo.

O sucesso da literatura brasileira nos Países Baixos deve-se ao talento tradutório de Willemsen e à sua capacidade de tratar a língua neerlandesa segundo os protocolos criativos que percebe dos escritores brasileiros no trato da língua portuguesa. A qualidade de seu trabalho como tradutor está intimamente ligada à sua singularidade, à singularidade que deixou marcada no arquivo que escolheu herdar e sobre o qual deitou sua contra-assinatura. Willemsen traduz e transgride na própria língua como forma de acolher a língua do outro. Isso posto, analisando o processo tradutório criativo de Willemsen, é necessário repensar o seu conceito de fidelidade, mesmo sabendo que ele próprio provavelmente não aproximaria fidelidade de recriação.

Esse procedimento é um bom exemplo da tradução criativa de que fala Haroldo de Campos - a estética tradutória antropofágica. "E esse é o teste dos testes da tradução de poesia. Tradução que não parece tradução. Poesia que é poesia” (CAMPOS, 1970, p. 13). Haroldo de Campos sempre pensou a tradução de poesia como uma "re-criação", ou seja, traduzir é reproduzir na outra língua o processo criativo que teve lugar na língua do original. Em suma, o que ele sempre fez foi transcriar. Para Haroldo de Campos, a "tradução de

${ }^{10}$ No original: "Op dat niveau functioneert poëzie net als een mop: zodra je die uitlegt - in andere woorden vertelt - is de loleraf". 
textos criativos será sempre recriação, ou criação paralela, autônoma, porém recíproca"; nela, "não se traduz apenas o significado", mas também a materialidade do acontecimento literário, suas propriedades sonoras e imagéticas. O significado será apenas "a baliza demarcatória do lugar da empresa recriadora" (CAMPOS, 1970, p. 13). Nas palavras de Cristina Monteiro de Castro Pereira,

Assumir a falta e transformá-la em trampolim para a criação é a solução apontada e adotada por Haroldo de Campos. O "impossível de se dizer" do original se transforma em espaço para a criação artística. Opondose à visão tradicionalista, que colocava o tradutor e seu texto numa posição secundária e subserviente em relação ao autor e ao original, teóricos como Walter Benjamin e Haroldo de Campos conquistam, para a tradução, sua autonomia (PEREIRA, 2004, [n.p.]). ${ }^{11}$

\section{Referências}

ANDRADE, O. Manifesto Antropófago (texto integral). Revista de Antropofagia, ano 1, n. 1, , p. 3 e 7 , maio 1928.

BENJAMIN, W. A tarefa do tradutor. In: A tarefa do tradutor de Benjamin. Tradução de Fernando Camacho. Belo Horizonte: Fale/UFMG, 2008.

BIYOGO, G. Adieu à Jacques Derrida: enjeux et perspectives de la déconstruction. Paris: L'Harmattan 2005.

CAMPOS, H. Metalinguagem. Petrópolis: Vozes, 1970.

COSTA, W. C. O Guimarães Rosa holandês de August Willemsen. Nonada, Porto Alegre, v. 10, n. 10, p. 179-189, dez. 2007.

DERRIDA, J.; ROUDINESCO, E. De quoi demain... Dialogue. Paris: Fayard, 2001.

JAKOBSON, R. Aspectos lingüísticos da tradução. In: Lingüistica e comunicação. Tradução de Izidoro Blikstein e José Paulo Paes. São Paulo: Cultrix, 1971. p. 63-72.

LAGES, S. K. Walter Benjamin: tradução e melancolia. São Paulo: Edusp: 2002. LAGES, S. K. Depois de Babel: Guimarães Rosa e a tradução. Nonada, Porto Alegre, v. 10, n. 10, p. 157-166, dez. 2007.

${ }^{11}<$ http://www.filologia.org.br/viiicnlf/>. 
PEREIRA, C. M. C. Transcriação: a tradução em jogo. In: CONGRESSO NACIONAL DE LINGÜÍSTICA E FILOLOGIA, 8., 2004, Rio de Janeiro. Cadernos do CNLF, série VIII, n 6. Disponível em: <http://www.filologia.org.br/ viiicnlf/>. Acesso em: 31 de jan. 2012.

ROSA, J. G. De derde oever van de rivier. Tradução e posfácio August Willemsen. Amsterdam: Meulenhoff, 1977.

ROSA, J. G. Grande sertão: veredas. 37. ed. Rio de Janeiro: Nova Fronteira, 1988.

ROSA, J. G. Diepe wildernis: de wegen. 3. ed. Tradução e posfácio de August Willemsen. Amsterdam: Meulenhoff, 2000.

SCHREIJ, T. O papel do tradutor: introdução da literatura lusófona na língua neerlandesa entre 1900 e 2008. 2009. 295 f. Dissertação (Portugese Taal em Cultuur - Masterprogramma Vertalen) - Universiteit Utrecht, Nederlands, 2009.

VEJMELKA, M. Guimarães Rosa na Alemanha: a metafísica enganosa. SCRIPTA, Belo Horizonte, v. 5, n. 10, p. 412-424, 2002.

WILLEMSEN, A. O autor da obra alheia. Revista Fragmentos, Florianópolis, v. 1, n. 1, p. 53-65, 1986.

WILLEMSEN, A. Het woord als gedicht - het boek als de wereld. In: ROSA, J. G. Diepe wildernis: de wegen. 3. ed. Tradução e posfácio de August Willemsen. Amsterdam: Meulenhoff, 2000.

WILLEMSEN, A. Ik dronk de koffie die ik zelf zette. Interview met vertaler/ schrijver August Willemsen. Meander: Literair E-Zine, Delft, afl. 316, Apr. 2007. Disponível em: <http://meandermagazine.net/magazines/mea316.html>. Acesso em: 15 jan. 2012.

Recebido em 9/1/2012. Aprovado em 6/5/2012. 